\title{
A Comprehensive Analysis of CGE Model-based Energy Policy of China
}

\author{
Zong Ke \\ Shan Dong university of science and technology, Shandong, China \\ YuanYuan \\ TaiShan College, Shandong Province, China
}

\begin{abstract}
Taken the main problem in China's current energy development as the studying background, this paper builds a dynamic computable general equilibrum model of 22 sectors. Based on 2002 China inputoutput table, this paper implements static analysis and dynamic analysis on China's energy policy by this CGE model. In static analysis, the impacts of oil and natural gas' price changing on GDP are checked. In dynamic analysis, the impacts of improving energy efficiency and developing recycling economy on economic development and energy demand are checked. Finally, this paper gives some policy suggestion.
\end{abstract}

KEYWORD: Energy Policy; Economic Growth; CGE Model

\section{PREFACE}

In the present situation, as petroleum price keeps rising and energy supply grows increasingly tense, the high energy consumption caused by the rapid development of heavy chemical industry has made new demands on China's energy system, and the imbalance between energy supply and demand has brought severe challenges to the sustainable development of China's economy, so energy conservation has become a basic state policy to which China must stick in the long term. However, the problem of energy pricing is always the core of China's energy policy, so as the international oil price rises, whether China can put a price on its oil and natural gas according to the international standards will affect its energy security[1]. Therefore, at present, the core problem of China's energy policy is energy saving problem and pricing problem.

Predictably, with the increase of oil and natural gas price and the development of energy saving and circular economy, China's economic development pattern will certainly be changed from extensive pattern to intensive pattern, the cost of economic growth will certainly increase, and the speed of economic growth will drop accordingly[2]. Thus it can be seen that energy policy will exert an influence on both socioeconomic development and energy demand. Coincidentally, classical economic theories can be used in CGE model to fully describe the economic conditions of all the social industrial sectors, so this paper will build a dynamic computable general equilibrium (CGE) model to predict the impact of an increase in oil and natural gas price, the enhancement of energy conservation and the development of material circulation on China's economic growth and energy demand.

\section{MODEL}

The postulated conditions for this model includes:

(1) This model is composed of 24 merchandise markets, including 22 commodity markets ( 5 energy markets) and 2 factor markets;

(2) According to the report of National Development and Reform Commission, let's suppose that the population will reach 1.368 billion in $2015,1.445$ billion in 2020 and 1.5 billion in 2030; suppose that the urbanization rate will reach $49 \%$ in $2015,58 \%$ in 2020 and $63 \%$ in 2030.

(3) Residents fall into two kinds: rural residents and urban residents; merchandise market, labor market and capital market are perfectly competitive; in the model, capital stock is endogenously determined while labor is exogenously given, and the above three markets are in a complete equilibrium state in every period; the residents and industrial sectors have a full predictable capacity; the period of simulating calculation is 28 years, from 2002 to 2030.

(4) In this model, a goal is set for economic growth: in the situation of slow technical progress, the average annual growth rate of GDP is $7 \%$; this economic growth rate is in line with the goal of economic growth set by the government. 
(5) Suppose that every department's import and export only has to do with its own gross output; the social cost of technical progress is negligible;

In this model, departmentalization is based on the input-output table of 42 Chinese sectors in 2002. Its principle: mark off the energy production sector and heavy industry sector in the secondary industry and the key dissipative sectors in the tertiary industry, and classify other sectors. This model divides social industry into 22 sectorss.

In this model, the industrial sectors use intermediate materials, labor forces and funds to produce merchandises. Intermediate materials refer to the inputs made by all industrial sectors in products, including energy and other resources, etc. The relationship between the synthesis and added value of intermediate inputs can be represented by Leontief function. Besides, in this paper, capital and labor force are calculated by Cobb-Douglas function and an added value is obtained. Then, the intermediate materials of all the industrial sectors used by this department are calculated by CobbDouglas function and the synthesis of intermediate inputs is obtained. Suppose that the techniques used by all the departments are constant returns to scale. Because of the linear identity of production technologies, in the given demand for commodities and price condition, the behavior of industrial sectors can be described by cost minimization. Utility function is calculated by the urban household consumption and rural resident consumption in subsectors, and the maximization of utility function conditioned by income can be used to determine the demand of the residents in subsectors for commodities; by taking economic growth goal as the cross-sectional condition for this model, and determining the extreme value of the utility function in infinite time domain, we can determine the parameters in the model that can reflect future incertitude, such as the discount rate of utility and the discount rate of income, etc.

\section{COMPUTATIONAL ANALYSIS}

\subsection{Parameter setting}

In this model, the energy consumption of physical units in different varieties is calculated by electrothermal equivalent in accordance with Energy Balance of China (Standard Quantity)-2002[3]. By analyzing the inflow and outflow of energy in each sector's using process, we can calculate the conversion coefficient of energy utilization, conversion coefficient of energy processing and loss ratio of energy transmission. The calculation of the conversion coefficient of energy utilization can be expressed as: the investment (monetary unit: yuan) made by the energy production department in the input-output table in some department subtracts the energy consumption this department in the inputoutput table (physical unit: kilogram of standard coal). The conversion coefficient of energy processing can be expressed as the ratio between the output and input of secondhand energy in the course of processing and conversion; the loss ratio of energy transmission can be expressed as the ratio between the transmission loss of each energy variety and the total demand for it. In the prediction and analysis made by this paper, these parameters need to be corrected based on scenario assumptions.

Tab.1 The impact of the rise in the crude oil and natural gas price on industrial added value (unit: \%o)

\begin{tabular}{|c|c|c|c|c|c|}
\hline Sectors & $10 \%$ & $30 \%$ & $50 \%$ & $70 \%$ & $100 \%$ \\
\hline 1 & -0.254 & -0.722 & -1.142 & -1.520 & -2.018 \\
\hline 2 & 1.026 & 3.044 & 5.016 & 6.945 & 9.758 \\
\hline 3 & -23.185 & -66.652 & -106.622 & -143.488 & -193.696 \\
\hline 4 & -0.396 & -1.114 & -1.744 & -2.298 & -3.007 \\
\hline 5 & -15.287 & -44.339 & -71.524 & -97.018 & -132.423 \\
\hline 6 & 0.003 & 0.029 & 0.079 & 0.149 & 0.285 \\
\hline 7 & -2.925 & -8.581 & -13.997 & -19.191 & -26.601 \\
\hline 8 & -0.987 & -2.868 & -4.637 & -6.306 & -8.640 \\
\hline 9 & -0.698 & -2.013 & -3.229 & -4.359 & -5.910 \\
\hline 10 & -0.504 & -1.463 & -2.362 & -3.209 & -4.392 \\
\hline 11 & -0.662 & -1.907 & -3.057 & -4.124 & -5.587 \\
\hline 12 & 2.716 & 7.986 & 13.055 & 17.937 & 24.942 \\
\hline 13 & -0.177 & -0.496 & -0.774 & -1.016 & -1.323 \\
\hline 14 & -0.182 & -0.525 & -0.846 & -1.146 & -1.562 \\
\hline 15 & 0.512 & 1.514 & 2.487 & 3.432 & 4.802 \\
\hline 16 & 0.588 & 1.755 & 2.907 & 4.043 & 5.716 \\
\hline 17 & -0.476 & -1.393 & -2.265 & -3.096 & -4.277 \\
\hline 18 & -1.952 & -5.691 & -9.227 & -12.581 & -17.304 \\
\hline 19 & 0.108 & 0.310 & 0.493 & 0.660 & 0.883 \\
\hline 20 & -0.734 & -2.170 & -3.565 & -4.920 & -6.884 \\
\hline 21 & 0.159 & 0.477 & 0.795 & 1.113 & 1.586 \\
\hline 22 & -0.489 & -1.408 & -2.257 & -3.044 & -4.121 \\
\hline Total & -0.907 & -2.614 & -4.192 & -5.656 & -7.665 \\
\hline
\end{tabular}

\subsection{Static analysis}

The result of static simulation calculation is illustrated in Tab.1. In the 10 situations, as the crude oil and natural gas price rises by $10 \%$ to $100 \%$, the added value of Sector 2 (coal mining and washing), Department 12 (waste and scrap), Sector 15 (papermaking, printing and stationery manufacturing), Sector 16 (water production and supply), Sector 19 (other secondary industries) and Sector 21 (wholesale \& retail trade and catering industry) changes positively. These computation results indicate that as the rise in crude oil price, coal production will increase, and other primary energy, such as coal, will replace crude oil; the recycling rate of waste and scrap will increase, and the circulation of materials will develop further, to make up for the 
shortfall of crude oil consumption. The light industry and second industry that have low demand for crude oil and petroleum products will increase production, and the production will develop towards low oil consumption; water production will increase, and low oil consumption will lead to high water consumption; wholesale and retail trade will increase, but the production in other tertiary industries, on the whole, will decrease. This shows that the rise in oil price will promote trade development. The added value of Sector 3 (crude oil and natural gas extraction) and Sector 5 (petroleum processing, coking and nuclear fuel processing) declines most dramatically, which shows that the rise in crude oil price will lead to not only a decline in crude oil production, but also a significant decrease in the production of petroleum products.

\subsection{Dynamic analysis}

This paper sets 7 scenarios of technological progress to simulate industrial technology upgrading, and strengthen the impact of such technological progress modes as efficiency of energy use and cyclic utilization rate of materials on energy intensity:

(1) Scenario 0 (baseline scenario): suppose that the parameters of technological progress will increase by $10 \%$ from 2002 to 2030 ;

(2) Scenario 1 (scenario of energy conservation strengthening): based on Scenario 0, suppose that the efficiency of energy use will increase year by year, and in 2030, the efficiency of energy use in social sectors will be $30 \%$ higher than 2002 ;

(3) Scenario 2 (scenario of energy conservation strengthening+ intermediate material circulation): Based on Scenario 1 (the efficiency of energy use in social sectors will increase by $30 \%$ ), suppose that in 2030 , the circulation utilization rate of materials in all departments will be $200 \%$ higher than 2002 , and the input of raw materials required for per unit output in each sector will be 5\% lower than 2002;

(4) Scenario 3 (scenario of energy conservation strengthening+ advanced material circulation): Based on Scenario 1 (the efficiency of energy use in social sectors will increase by $30 \%$ ), suppose that in 2030 , the circulation utilization rate of materials in all departments will be $400 \%$ higher than 2002, and the input of raw materials required for per unit output in each sector will be $10 \%$ lower than 2002.

In this model, the balance of energy market can be described as that the total supply of all energy varieties is equal to the total demand, total energy demand includes the energy consumption in production and the energy consumption in living, total energy supply includes gross energy output and the net value of energy import and export. To deduct the energy consumption calculated repeatedly in the process of energy processing and conversion from the total demand for energy can figure out total energy consumption. In this model, the total energy consumption involves raw coal and its products, crude oil and its products, natural gas and electric power. According to the using process, total energy consumption includes final consumption, processing $\&$ conversion loss and transmission loss. In the calculation made in this model, the conversion loss of energy processing can be expressed as the difference between the input and output of energy in the course of processing and conversion, and it has something to do with energy efficiency ratio; energy transmission loss is in direct proportion to its loss ratio; to subtract energy processing \& conversion and transmission loss from gross energy demand can figure out final energy consumption.

By dynamic simulating calculation, the energy flow analysis under various scenarios in 2002 and 2030 is shown in Tab.2, Tab.3, Tab.4 and Tab.5. To make a balance calculation of the above energy flow analysis sheets can master the energy flow status and actual energy efficiency in using process. Compared to the baseline scenario, in the various scenarios of energy conservation strengthening, the conversion loss and transmission loss of Sector 6 (power and hot water generation and supply) decline sharply, so that the input of such energy as coal required by Sector 6 in energy conversion process falls sharply. Meanwhile, compared with the initial scenario in 2002 , the ratio of such high-quality energy as power, hot water, oil, natural and oil products to final energy consumption rises somewhat, while the share of coal in final consumption declines somewhat.

Tab.2 Energy flow analysis of Scenario 0 in 2030

\begin{tabular}{|c|c|c|c|}
\hline \multicolumn{2}{|c|}{} & Total & Conversion output \\
\hline \multirow{4}{*}{ Conversion input } & Sector 2 & 113149 & 106482 \\
\cline { 2 - 4 } & Sector 3 & & \\
\cline { 2 - 4 } & Sector 5 & 378784 & 367937 \\
\cline { 2 - 4 } & Sector 6 & 471147 & 204151 \\
\cline { 2 - 4 } & Sector 7 & 10440 & 7437 \\
\hline \multicolumn{2}{|c|}{ Conversion loss } & 287513 & \\
\hline \multicolumn{2}{|c|}{ Transmission loss } & 14783 & \\
\hline \multicolumn{2}{|c|}{ Final consumption } & 863176 & \\
\hline \multicolumn{2}{|c|}{ Total energy consumption } & 1165472 & \\
\hline
\end{tabular}

Tab.3 Energy flow analysis of Scenario 1 in 2030

\begin{tabular}{|c|c|c|c|}
\hline \multicolumn{2}{|c|}{} & Total & Conversion output \\
\hline \multirow{4}{*}{ Conversion input } & Sector 2 & 55364 & 52102 \\
\cline { 2 - 4 } & Sector 3 & & \\
\cline { 2 - 4 } & Sector 5 & 225705 & 219242 \\
\cline { 2 - 4 } & Sector 6 & 265440 & 149522 \\
\cline { 2 - 4 } & Sector 7 & 7397 & 5269 \\
\hline \multicolumn{2}{|c|}{ Conversion loss } & 127772 & \\
\hline \multicolumn{2}{|c|}{ Transmission loss } & 8029 & \\
\hline \multicolumn{2}{|c|}{ Final consumption } & 628070 & \\
\hline \multicolumn{2}{|c|}{ Total energy consumption } & 763871 & \\
\hline
\end{tabular}


Tab.4 Energy flow analysis of Scenario 2 in 2030

\begin{tabular}{|c|c|c|c|}
\hline \multicolumn{2}{|c|}{} & Total & Conversion output \\
\hline \multirow{4}{*}{ Conversion input } & Sector 2 & 58183 & 54754 \\
\cline { 2 - 4 } & Sector 3 & & \\
\cline { 2 - 4 } & Sector 5 & 238681 & 231846 \\
\cline { 2 - 4 } & Sector 6 & 281865 & 158774 \\
\cline { 2 - 4 } & Sector 7 & 8019 & 5712 \\
\hline \multicolumn{2}{|c|}{ Conversion loss } & 135661 & \\
\hline \multicolumn{2}{|c|}{ Transmission loss } & 8489 & \\
\hline \multicolumn{2}{|c|}{ Final consumption } & 658162 & \\
\hline \multicolumn{2}{|c|}{ Total energy consumption } & 802312 & \\
\hline
\end{tabular}

The aggregative energy economy indicators of all scenarios in 2030 are shown in Tab.7. Compared to the baseline scenario, the average annual growth rate of GDP in the scenarios of energy conservation strengthening with circulation of materials will increase somewhat, while the average annual growth rate of GDP in the scenarios of energy conservation strengthening without circulation of materials will decline somewhat. If energy saving cost is considered, it will decline more. In addition, energy conservation strengthening can lead to a sharp decline in energy intensity. The scenarios of energy conservation strengthening with circulation of materials will lead to a sharper decline in energy intensity. Particularly, in the scenarios of energy conservation strengthening with advanced circulation of materials, energy consumption elasticity coefficient is only 0.6. Compared to the baseline scenario, it decreases by $40 \%$.

Tab.5 Energy flow analysis of Scenario 3 in 2030

\begin{tabular}{|c|c|c|c|}
\hline \multicolumn{2}{|c|}{} & Total & Conversion output \\
\hline \multirow{4}{*}{ Conversion input } & Sector 2 & 60507 & 56942 \\
\cline { 2 - 4 } & Sector 3 & & \\
\cline { 2 - 4 } & Sector 5 & 248987 & 241857 \\
\cline { 2 - 4 } & Sector 6 & 295103 & 166231 \\
\cline { 2 - 4 } & Sector 7 & 8550 & 7409 \\
\hline \multicolumn{2}{|c|}{ Conversion loss } & 140708 & \\
\hline \multicolumn{2}{|c|}{ Transmission loss } & 8849 & \\
\hline \multicolumn{2}{|c|}{ Final consumption } & 681323 & \\
\hline \multicolumn{2}{|c|}{ Total energy consumption } & 830880 & \\
\hline
\end{tabular}

Tab.6 the aggregative energy economy indicators of all scenarios in 2030

\begin{tabular}{|c|c|c|c|c|c|}
\hline & & Scenario 0 & Scenario 1 & Scenario 2 & Scenario 3 \\
\hline \multicolumn{2}{|c|}{ Average annual growth rate of GDP (\%) } & 7.175 & 7.061 & 7.385 & 7.642 \\
\hline \multirow{4}{*}{ Energy intensity } & Social sectors (kgce/104yuan GDP) & 1034.07 & 651.81 & 623.15 & 597.96 \\
\hline & Rural residents (kgce/104yuan GDP) & 29.64 & 29.67 & 29.86 & 30.30 \\
\hline & Urban residents (kgce/104yuan GDP) & 112.88 & 113.04 & 113.90 & 114.50 \\
\hline & Total (kgce/104yuan GDP) & 1176.59 & 794.52 & 766.91 & 742.76 \\
\hline \multicolumn{2}{|c|}{ Elastic coefficient of energy demand $(\% / \%)$} & 1.022 & 0.657 & 0.620 & 0.600 \\
\hline
\end{tabular}

\section{CONCLUSION}

In the medium and long term, China will always stay in the stage of heavy chemical industry, so the rapid development of energy consumption is unavoidable. Raising the price of such high-quality energy as oil and natural gas will help urge China's economic structure to develop towards low oil consumption. Energy conservation strengthening will produce adverse impacts on GDP growth; however, in the same time of strengthening energy conservation, to energetically develop circular economy can not only promote GDP growth, but also further enhance energy-saving effect. Moreover, along with the development of Chinese urbanization and the improvement of its economic level, in the terminal energy structure, the share of coal will decrease little by little, and the share of such high-quality energy as oil, natural gas, oil products and electricity, etc. will increases gradually, because clean energy will prevail. Therefore, while implementing strict energysaving and emission-reducing policies, to promote the development of clean energy will be China's only choice in the medium and long term to guarantee energy safety.

\section{ACKNOWLEDGEMENTS}

This paper sponsored by the China's Ministry of education of Humanities and social science project (14YJCZH236) and the 2014 Shandong Province Education Department of Humanities and Social Sciences project.

\section{REFERENCES}

[1] China Statistical Yearbook of 2013, compiled by National Bureau of Statistics of the People's Republic of China, China Statistics Press, 2014.

[2] The Input-output Table of China in 2002, compiled by Department of National Economic Accounting of National Bureau of Statistics of the People's Republic of China, China Statistics Press, 2006.

[3] China Energy Statistical Yearbook of 2013, compiled by Department of Industry \& Transportation Statistics of National Bureau of Statistics of the People's Republic of China, and Bureau of Energy of National Development and Reform Commission, China Statistics Press, 2014. 